\title{
Idéias e concepções permeando a formação profissional entre estudantes das ciências da saúde da UFRN: um olhar da Psicologia Social
}

\author{
Martha Traverso-Yépez \\ Normanda Araújo de Morais \\ Universidade Federal do Rio Grande do Norte
}

\begin{abstract}
Resumo
O artigo apresenta as concepções dos estudantes dos diferentes cursos da área da saúde da Universidade Federal do Rio Grande do Norte acerca de aspectos relevantes da sua formação, tais como motivos que levaram à escolha do curso, objetivos e expectativas profissionais e forma como concebem o relacionamento profissional-paciente/cliente. Acredita-se que o processo de formação profissional seja um espaço privilegiado de estudo das idéias, valores e concepções que estão permeando as práticas de saúde. Considera-se, também, que mudanças nas atuais práticas de saúde requerem não somente uma reformulação estrutural do setor, mas também uma auto-avaliação conceitual e ideológica na forma desse futuro profissional pensar o seu fazer. Os resultados apontam para uma formação que tende a negligenciar a complexidade e multideterminação dos fenômenos humanos e a privilegiar os aspectos teóricos e técnicos, em detrimento do contexto humano da atuação profissional.
\end{abstract}

Palavras-chave: práticas de saúde; processos de significação; formação profissional; processos de humanização

\begin{abstract}
Ideas and conceptions permeating professional training among UFRN health courses students. This paper presents the conceptions of students of Universidade Federal do Rio Grande do Norte health courses about relevant psychosocial aspects related with their training process, such as motives for choosing that course, expectations and professional targets and how the professional-client/patient relationship is conceived. It is believed that the professional training process is a privileged space of study of ideas, values and conceptions permeating the health practices. It is also considered that changes in the actual health practices are possible not only through a structural reformulation of the sector, but also through conceptual and ideological selfevaluation of the way that this future professional conceives his practice. Results point out for a training process that tends to neglect the complexity and multidimensionality of the human life and favor theoretical and technical aspects underrating the human aspects of professional practice.
\end{abstract}

Keywords: health practices; meaning process; professional training; humanization process

$\mathrm{N}$ as últimas décadas, uma multiplicidade de vozes vem demandando por uma reforma educacional nas ciências da saúde a partir do reconhecimento do direito à saúde e da responsabilidade da sociedade em garantir os seus cuidados básicos. Essa demanda não apenas enfatiza a necessidade de a formação universitária adaptar-se ao processo de rápidas mudanças gerado por novos conhecimentos e tecnologias, mas também aprender a colocar esses conhecimentos a serviço das transformações que demanda a crítica realidade sócio-estrutural da saúde de grande parte da população (Almeida, Feuerwerker, \& Llanos, 1999; Byrne \& Rozental, 1994; Kissil \& Chavez, 1994; Organização Pan-americana de Saúde, 1994; Pierantoni \& Machado, 1994).

Observa-se que tanto as práticas assistenciais como as educativas estão ligadas não apenas aos avanços científicos e tecnológicos, mas aos modelos de práticas vigentes condicionados por concepções e valores desenvolvidos sóciohistoricamente. Tais concepções constituem um fenômeno complexo, permeado por condicionantes não apenas econômicos, mas também políticos, sociais e culturais; definidor, portanto, de um contexto psicossocial contraditório de significações, valores e práticas, objeto privilegiado de estudo da Psicologia Social crítica (Traverso, 1999).

A pesquisa objetivou esclarecer os processos de significação relacionados com saúde-doença e as práticas em saúde, bem como sobre a formação profissional entre estudantes dos diferentes cursos da área da saúde na Universidade Federal do Rio Grande do Norte (UFRN). O presente artigo enfoca as idéias, concepções e expectativas que estão permeando a escolha do curso, a formação profissional e a relação profissi- 
onal-paciente/cliente, visando a definição de fundamentos que possibilitem uma formação mais humanizada e coerente com a realidade da assistência à saúde em nosso contexto.

\section{As práticas de saúde e a formação profissional}

Com as transformações sociais decorrentes do desenvolvimento científico e tecnológico, e do processo de industrialização verificados a partir do século XVIII, observou-se a emergência da consciência sanitária e a institucionalização e pluralização das intervenções em saúde. Essas mudanças, segundo Rosen (1994), teriam gerado os alicerces da medicina científica atual. Esta foi se fortalecendo no decorrer do século XX, com o predomínio do chamado modelo biomédico, caracterizado pela divisão cartesiana corpo-mente, pelo biologismo, pelo mecanicismo, pelo individualismo, pela especialização, pela exclusão das práticas alternativas, pela tecnificação do ato médico, pela ênfase na medicina curativa e pela concentração de recursos muito sofisticados e de alto custo nos centros privados de atendimento (Capra, 1982; Silva Jr., 1998).

Esses elementos estão, portanto, bastante arraigados na formação dos estudantes das ciências da saúde, especialmente na Medicina, disciplina pioneira em lidar com as doenças. A emergência dos mercados profissionais decorrente do desenvolvimento do sistema capitalista condicionou a necessidade da institucionalização desse mercado e da produção de serviços e profissionais "estandardizados", passando a educação formal a ter um papel fundamental na regularização e normatização desses profissionais (Pierantoni \& Machado, 1994). O Relatório Flexner das primeiras décadas do século XX é citado com freqüência como o momento-chave nesse processo de estandardização na área do ensino médico (Byrne \& Rozental, 1994; Organização Pan-Americana de Saúde, 1994; Rosen, 1994; Silva Jr., 1998). Almejou justamente unificar os currículos das escolas de medicina e sistematizar o conhecimento médico segundo os aportes do modelo biomédico.

No que se refere à formação profissional, a academia virou o espaço de aprendizado e titulação, status social e credenciamento para exercer uma atividade específica. Aliás, como qualquer instituição social, ela está também perpassada pelas contradições sociais que caracterizam o sistema. Como expressa Boltanski (1989),

sua atividade situa-se na interferência de três lógicas diferentes e até contraditórias: a lógica do interesse humanitário (fazer tudo pelo doente), da racionalidade e do interesse científico (fazer progredir a ciência) e enfim, do lucro e da rentabilidade econômica (ganhar dinheiro). (p. 41)

Segundo a Organização Pan-Americana de Saúde (1994), "a escola (médica) em sua especificidade institucional oferece essencialmente qualificação técnica e de trabalho, gerando e transmitindo uma determinada cultura profissional dominante e reproduzindo o modelo científico hegemônico" (p. 12). Destaca-se, assim, a necessidade de mudanças nas práticas de ensino e formação profissional, criticando-se diferentes aspectos dessa formação, tais como a educação baseada na memorização e repetição, que inibe o pensamento reflexi- vo e crítico, bem como a pouca correlação entre o conhecimento adquirido e a futura prática profissional (Byrne \& Rozental, 1994; Organização Pan-Americana de Saúde, 1994; Pierantoni \& Machado, 1994). Essas mudanças passam, sobretudo, pela necessidade de se formar alunos capazes de pensar criticamente e compreender a permanente interdependência existente entre as dimensões biológicas, psicológicas e sócio-ambientais do processo saúde-doença, a fim de trabalhar melhor a prevenção e a promoção da saúde, bem como de desenvolver práticas mais humanizadas nas formas de lidar com o paciente.

A relevância da permanente interdependência entre essas diversas dimensões parte do reconhecimento, nas últimas décadas, de uma visão mais abrangente e complexa do processo saúde-doença e da conseqüente incorporação de profissionais de outras áreas na preocupação por esse processo. Contudo, quando se fala de formação em ciências da saúde, geralmente os autores ficam ainda restritos ao campo da formação em Medicina (Byrne \& Rozental, 1994; Organização Pan-Americana de Saúde, 1994). Tende-se a esquecer a incorporação das novas áreas do saber ao campo das práticas em saúde, desconsiderando o caráter multifacetado e processual da temática, reconhecido oficialmente no Brasil, a partir da Constituição de 1988. Por outro lado, deve-se destacar que até agora, como Pierantoni e Machado (1994) apontam, os currículos propostos por diversos cursos de diferentes instituições de ensino falham ao não definir a concepção de saúde como eixo integrador e ao não considerar os modos de inserção das diferentes categorias profissionais nesse processo. $\mathrm{O}$ grande problema talvez seja a ausência, no campo das ciências humanas, de uma consideração permanente pela temática saúde a partir de sua versão positiva, estreitamente relacionada com o sentido que cada indivíduo atribui à sua vida.

Segundo Canguilhem (1990), o conceito de saúde seria a maior disponibilidade de escolha entre os vários modos de andar a vida. É a definição implícita na etimologia da palavra "saúde", que significa são, salvo, íntegro. Essa noção de integridade vai de encontro à fragmentação tradicional em saúde física, mental e social, pressupondo entender saúde na interface de diferentes campos de saber, já que nenhuma disciplina isoladamente dá conta dessa complexidade. Contudo, foi o reducionismo do pensamento linear do modelo positivista que condicionou tal visão restrita de saúde e a hegemonia da versão biomédica, promovendo, ainda, a concentração de cada área de saber, num domínio técnico específico. Ao fazer isso, esqueceu a necessidade de um olhar mais abrangente, transformando a proposta de "equipe de saúde" numa retórica carente de qualquer base de sustentação real (Pierantoni \& Machado, 1994). Contudo, esse pensar interdisciplinar não finda sendo apenas um problema teóricoepistemológico, mas é, de fato, um problema político ${ }^{1}$. Como Canesqui (1995) destaca:

as discussões a respeito da inter e transdisciplinaridade, além de adentrarem o plano epistemológico, envolvem o da política, 
desde que o campo científico, como nos lembra Bourdieu, comporta relações de poder, conflitos, disputas associados à concentração do quantum de capital cultural e simbólico acumulados entre os seus distintos componentes, conferindo-lhes graus distintos de legitimidade. (p. 33)

Conseqüentemente, o médico ainda é visto como agente principal nos cuidados à saúde em função do modelo hegemônico vigente, em detrimento dos demais profissionais que deveriam ter uma participação mais ativa (Traverso, 2001). Por isso, quando se fala de relação profissional-paciente/cliente - talvez um dos elementos mais relevantes para o processo de humanização das práticas da saúde - os estudos tendem a citar exclusivamente a relação que se estabelece com o médico.

Rodríguez-Marín (1995) considera a relação médico-paciente como aspecto central da assistência sanitária. Ele aponta as quatro formas típicas de controle dessa relação descritas por Roter e Hall (1992, citados por Rodríguez-Marín, 1995): paternalista, na qual o médico domina a tomada de decisões com respeito à informação e serviços; clientelista, a qual define a consulta médica como uma transação de mercado; mutualista, em que cada um dos participantes contribui com as forças e recursos de que dispõe e a relação torna-se um encontro entre iguais; e ausente, caracterizada por uma total ausência de controle tanto por parte do paciente quanto do médico. Além disso, é importante reconhecer, com Boltanski (1989), que a relação médico-paciente não acontece no vácuo, mas é uma relação de classe na qual o médico adota um comportamento diferente conforme a classe social do seu paciente/cliente.

Ainda sobre essa temática, tanto a Medicina psicossomática quanto a Psicologia médica têm oferecido valiosas contribuições ao destacar que o sucesso da prática médica não é apenas uma questão de qualificação técnica, mas conseqüência do estabelecimento de um bom relacionamento com o paciente. Segundo Melo Filho (1988), a interação médico e paciente representa, acima de tudo, um encontro humano, tendo essa relação características próprias, de acordo com as pessoas envolvidas nesses papéis sociais e o processo de interação entre ambos.

Campos (1997) sugere que o profissional da saúde deveria ser formado para propiciar e aumentar o que o autor denomina de "capacidade de autonomia do paciente". Ou seja, fazer com que o paciente conheça mais sobre seu corpo, sua doença e as suas relações com o meio social, fazendo com que ele tenha um papel mais ativo diante de seus problemas. Considera-se que isso implicaria o desenvolvimento de uma maior sensibilização entre os estudantes sobre os aspectos psicossociais, filosóficos e éticos - além dos puramente técnicos - relacionados com as práticas de saúde nas quais estão envolvidos.

\section{Método}

Objetivou-se no presente estudo esclarecer os processos de significação com relação à formação profissional entre estudantes das ciências da saúde, almejando aprofundar o conhecimento do universo simbólico que está permeando essas práticas de formação. A pesquisa foi desenvolvida com uma amostra de 264 estudantes pertencentes aos cursos que compõem o campo da saúde (Tabela 1). Para a coleta de dados, foi utilizado um questionário de perguntas abertas sobre as temáticas objeto da pesquisa e os dados sóciodemográficos dos estudantes participantes (ver Apêndice).

Tabela 1

Caracterização dos participantes

\begin{tabular}{lcc}
\hline \multicolumn{1}{c}{ Curso } & Número de estudantes & $\%$ \\
\hline Medicina & 47 & 17,8 \\
Fisioterapia & 36 & 13,6 \\
Enfermagem & 35 & 13,3 \\
Psicologia & 32 & 12,1 \\
Farmácia & 31 & 11,7 \\
Odontologia & 30 & 11,4 \\
Serviço Social & 29 & 11,0 \\
Nutrição & 24 & 9,1 \\
\hline \multicolumn{1}{c}{ Total } & 264 & 100 \\
\hline
\end{tabular}

O processo de análise das respostas do questionário implicou, em primeiro lugar, reler várias vezes as diferentes respostas obtidas, confrontando as perspectivas e significados produzidos pelos participantes. De acordo com Minayo (1998), objetivou-se, "compreender o modo de funcionamento, os princípios de organização e as formas de produção social do sentido" (p. 211). Numa segunda etapa, procedeuse ao processo de categorização, agrupando essas respostas em expressões capazes de abranger elementos, aspectos e características comuns expressas numa mesma idéia. Visouse, assim, o aperfeiçoamento dos conceitos que estão na base das categorias que surgiram para cada matriz de respostas, almejando a redução progressiva das categorias a partir do mesmo vocabulário conceitual. Num terceiro momento, as respostas categorizadas foram ingressadas no programa estatístico SPSS (Statistical Package for Social Sciences), para o processamento e leitura através de estatísticas descritivas. As estatísticas foram, assim, um complemento de sistematização à riqueza e complexidade das diferentes versões dos participantes da pesquisa.

\section{Resultados e Discussão}

A amostra dos participantes apresenta-se predominantemente feminina $(75,4 \%)$, estando a maioria $(86,1 \%)$ na faixa entre 18 e 25 anos. Da amostra, $30 \%$ têm renda familiar entre 5 e 10 salários mínimos e $43 \%$ entre 10 e 30 salários mínimos, o que situa a maioria dos estudantes na classe média. Apenas $14 \%$ têm uma renda familiar maior que 30 salários, estando esta última parcela concentrada majoritariamente nos cursos de Medicina e Odontologia. Grande parte dos estudantes é solteira $(87,1 \%)$ e $75 \%$ destes são de religião católica, embora apenas $48 \%$ freqüente a igreja regularmente.

Os "motivos que levaram os estudantes a escolherem o curso" (Tabela 2) giram em torno da identificação/interesse com as atividades de cada curso e do desejo de realização profissional/ pessoal (44,6\%), especialmente em função do contato com as práticas de profissionais significativos nas vidas deles, o que demonstra a influência do processo de socialização. 
Tabela 2

Motivos da escolha do curso

\begin{tabular}{lc}
\hline \multicolumn{1}{c}{ Categorias } & $\%$ \\
\hline Identificação com o curso/vocação/realização profissional/pessoal & 44,6 \\
Ajudar de acordo com as atividades do curso & 16,6 \\
Ajudar de uma forma geral & 11,1 \\
Possibilidades de contatos interpessoais & 11,1 \\
Impossibilidade de fazer o curso de preferência & 6,2 \\
Realização financeira & 5,9 \\
Não sabe/não respondeu & 4,5 \\
\hline Total & 100 \\
\hline
\end{tabular}

Desde muito novo eu já pensava em fazer medicina. É um curso que eu admiro e que já tinha conhecimento prévio de como era ser um médico (meus pais o são). (Estudante de Medicina $-4^{\underline{o}}$ período)

Tenho uma amiga que é fisioterapeuta e o trabalho que ela faz acabou chamando a minha atenção. (Estudante de Fisioterapia - $1^{\underline{0}}$ período)

A vontade de ajudar ao próximo, aliado à influência de parentes e vocação. (Estudante de Serviço Social - 2º período)

Escolhi esse curso por vocação, porque acho que tem muito a ver comigo. Porque vi nele a possibilidade de ajudar muitas pessoas e sentir-me gratificada ao final. (Estudante de Enfermagem $-3^{\underline{0}}$ período)

A primeira motivação é a realização pessoal seguida do intuito de que com essa profissão possa vir a ajudar aos que me procurarem... (Estudante de Psicologia - $4^{\underline{0}}$ período)

Observa-se que o intuito de ajudar as pessoas por intermédio das atividades específicas de cada curso $(16,6 \%)$ e de ajudar as pessoas sem especificar a maneira de fazê-la $(11,1 \%)$, foram também ressaltadas pelos estudantes. Contudo, esta ajuda é, geralmente, marcada por um discurso assistencialista, pois para muitos dos estudantes, o profissional será a parte principal na resolução dos problemas trazidos pelos pacientes:

A oportunidade de poder trabalhar de perto com as pessoas e poder como profissional resolver seus problemas lhes dando esperança, ter a oportunidade de conhecer cada pessoa individualmente e dentro de seus limites de suas possibilidades dar conselhos que possam manter sua "boa condição de vida". (Estudante de Medicina - $4^{\underline{0}}$ período)

A escolha do curso também foi motivada pelo fato de gostar da possibilidade de conhecer e aprender com as pessoas, lidando com estas no dia-a-dia da profissão ("Possibilidades de contatos interpessoais" - 11,1\%), discurso presente especialmente entre estudantes da Psicologia e de Serviço Social. Outra categoria que merece destaque é a escolha da futura profissão por "Impossibilidade de fazer o curso de preferência" $(6,2 \%)$, presente, especialmente, entre alunos da área biomédica que desejavam cursar Medicina ou Odontologia. Percebe-se, muitas vezes, a frustração desses estudantes, que mesmo estando nos últimos períodos de formação, ainda se lamentam por não terem feito o curso desejado:
Foi por segunda opção. Eu queria Odontologia. (Estudante de Nutrição - $9^{-0}$ período)

O vestibular que é errado e não deixa que eu faça Medicina, pois tenho certeza que tenho capacidade. Mas “odonto" não é ruim. Espero ter todos os benefícios de um médico, embora seja bem difícil. (Estudante de Odontologia - $2^{\underline{0}}$ período)

$\mathrm{O}$ aspecto financeiro foi mencionado como relevante em $5,9 \%$ das respostas, o que lembra a afirmação de Boltanski (1998) sobre a lógica da rentabilidade financeira, um forte estímulo para o desenvolvimento profissional na sociedade capitalista:

Aos sete anos conheci um médico muito idealista, seu exemplo de vida e, confesso, confortável situação econômica me motivaram a escolher essa profissão. (Estudante de Medicina $4^{\mathrm{o}}$ período)

Admiração pela profissão; sentimento de aptidão; influência familiar positiva (irmãos); possibilidade de realização profissional e financeira associadas. (Estudante de Medicina $12^{\mathrm{o}}$ período)

Dentre "Principais objetivos da futura carreira profissional" (Tabela 3), os estudantes destacaram a possibilidade de ajudar as pessoas por intermédio das atividades desenvolvidas por cada curso $(78,2 \%)$. Seja restaurando ou "devolvendolhes a saúde física", respostas muito comuns aos cursos da área biomédica, ou "ajudar às pessoas a se compreenderem", no caso do curso de Psicologia e "lutar pelos direitos dos cidadãos", especificamente no curso de Serviço Social. Destacou-se, portanto, a tendência dos alunos a limitarem a descrição de suas práticas em função das atividades específicas de cada área de conhecimento, sentindo-se, portanto, a falta de um eixo integrador centrado na preocupação pela saúde num sentido mais abrangente (Pierantoni \& Machado, 1994).

Tabela 3

Principais objetivos

\begin{tabular}{lc}
\hline \multicolumn{1}{c}{ Categorias } & $\%$ \\
\hline Ajudar de acordo com as atividades do curso & 78,2 \\
Ajudar de uma forma geral & 11,5 \\
Realização profissional/pessoal & 6,0 \\
Realização financeira & 4,3 \\
\hline Total & 100 \\
\hline
\end{tabular}


As respostas categorizadas como "Realização pessoal e profissional" e "Realização financeira", ainda são destacadas como objetivos da futura prática, mas num percentual de respostas bem menor se comparado ao principal objetivo: "Ajudar de acordo com as atividades do curso". Percebe-se que a lógica humanitarista prevalece significativamente em relação às outras duas lógicas: a profissional e a financeira (Boltanski, 1989). Contudo, fica difícil avaliar em que proporção esse tipo de posicionamento está condicionado pela tendência dos participantes a dar a resposta socialmente aceitável.

Questionados sobre os "aspectos indispensáveis na formação profissional”, fica evidente a prevalência da preocupação por garantir o sucesso profissional, também ratificado quando questionados sobre as suas expectativas com relação ao futuro, que giram em torno de serem reconhecidos profissionalmente quanto aos aspectos econômicos e de status. Assim, os estudantes priorizaram a aquisição de um sólido "Conhecimento teórico" (23,6\%) através de depoimentos enfatizando a necessidade de um "bom referencial teórico", "boa capacitação teórica", "formação técnica" e até "cursos de pós-graduação" como pré-requisito para uma boa qualificação profissional. Outras respostas assinalaram a necessidade de vincular a teoria com a prática ("Conhecimento teórico e prático" - 10,7\%). A "necessidade de praticar durante a formação acadêmica os conhecimentos adquiridos" e o "aprender fazendo" são para alguns estudantes aspectos relevantes para garantir no futuro uma atuação profissional mais efetiva, bem como a "vocação profissional" $(8,5 \%)$, no sentido de gostar do que faz, amor pela profissão e profissionalismo.

Me empenhar para aprender o máximo que puder. (Estudante de Enfermagem - $4^{\underline{o}}$ período)

As experiências adquiridas no contato com os clientes durante os blocos de aula-prática e os estágios supervisionados. (Estudante de Enfermagem - $7^{\underline{0}}$ período)

Dedicação, muito estudo, interesse, força de vontade, caráter, enfim, tem de se lutar para alcançar o objetivo desejado. (Estudante de Farmácia - $4^{\underline{0}}$ período)

Muita garra, muita vontade e ser persistente no que quero. (Estudante de Farmácia - $4^{\underline{0}}$ período)

Nesta questão, os estudantes também destacaram como indispensáveis na formação acadêmica, a presença de atributos e traços de personalidade considerados relevantes na vida profissional, como "empenho, iniciativa, determinação" $(16,7 \%)$, expressos através dos atributos de competência, garra para resolver problemas, ter iniciativa, força de vontade e ambição. Muitos estudantes apresentaram a necessidade de serem ativos e empreendedores em virtude de um mercado profissional que exige hoje um profissional competitivo, qualificado e até "agressivo" para vencer as limitações e adversidades do contexto social.

Contudo, não deixam de ser apontados, também, atributos morais e de consideração pelo outro, como "honestidade, caráter" (14,0\%), "paciência, equilíbrio" $(7,9 \%)$, "solidariedade, vontade de ajudar" $(7,4 \%)$ e "habilidade de relacionar-se com as pessoas" $(4,4 \%)$, lembrando a peculiaridade da profissão de lidarem com seres humanos.

Ratifica-se essa tendência quando questionados especificamente sobre as "características de personalidade" necessárias para a prática profissional. Enquanto em 28,4\% das respostas se enfatizam traços mais agressivos e centrados em si mesmo ("empenho, iniciativa e determinação, talento, profissionalismo"), a grande maioria das respostas $(68,5 \%)$ expressa atributos e traços de personalidade centrados na preocupação pelo paciente/cliente:

Humanidade (ver os pacientes como seres humanos e não como objetos de trabalho); sinceridade (dizer sempre ao paciente o que sabe a respeito da patologia dele); solidariedade (ter o sentimento de querer ajudar realmente estas pessoas); responsabilidade (saber sempre o que fazer e quais as minhas reais possibilidades); cumplicidade (fazer o paciente ter confiança em nós terapeutas) (Estudante de Fisioterapia - $7^{\underline{0}}$ período)

Ética, disciplina, responsabilidade e respeito para com o ser humano, já que é ele, de uma forma ou de outra, o objetivo principal da profissão. (Estudante de Farmácia - $4^{\underline{0}}$ período)

Quanto às "expectativas profissionais" (Tabela 4), os estudantes enfatizaram o anseio de "Serem reconhecidos profissionalmente" $(41,9 \%)$ em expressões tais como ter sucesso, atingir a realização profissional e pessoal, vencer profissionalmente, superar obstáculos, obter reconhecimento por parte dos pacientes e dos profissionais e exercer a profissão com dignidade aplicando os conhecimentos adquiridos. Destaca, ainda, a perspectiva de "ajudar" através da prática profissional colocada em 10,5\% das respostas. Manter-se atualizado em virtude das constantes descobertas científicas ou como meio para uma melhor inserção no mercado de trabalho ou para melhor atender aos pacientes, também faz parte das expectativas dos estudantes, sintetizada na categoria "Continuar estudando após a graduação” (10,5\%).

Tabela 4

Expectativas profissionais

\begin{tabular}{lc}
\hline \multicolumn{1}{c}{ Categorias } & $\%$ \\
\hline Ser reconhecido profissionalmente / Aplicar os conhecimentos adquiridos & 41,9 \\
Ajudar as pessoas & 10,5 \\
Continuar estudando & 10,5 \\
Boas expectativas & 9,8 \\
Ser bem sucedido financeiramente / Ser autônomo & 9,8 \\
Espera encontrar dificuldades & 8,1 \\
Sobreviver com a profissão & 2,7 \\
Espera ter condições de trabalho de qualidade & 2,0 \\
Não sabe / Não respondeu & 4,7 \\
\hline Total & 100 \\
\hline
\end{tabular}


Quero ser um bom médico, reconhecido não apenas pelos pacientes, mas também pelos demais colegas de profissão. (Estudante de Medicina - $4^{\underline{0}}$ período)

Sempre que possível reciclar, adquirir novos conhecimentos, de forma que torne o meu trabalho mais produtivo e reconhecido. (Estudante de Psicologia - $10^{\circ}$ período)

Acho que o mercado está bastante competitivo, por isso o profissional deve ser o mais qualificado possível... (Estudante de Farmácia - $7^{\underline{0}}$ período)

Estou terminando o curso um pouco apreensivo, pois necessito fazer especialização, supervisão, e tudo é muito caro. Pretendo abrir uma clínica e paralelamente investir na carreira acadêmica, com empenho. (Estudante de Psicologia - $10^{\circ}$ período)

Percebe-se que, ao lado daqueles que apontam "Ser bem sucedido financeiramente / Ser autônomo" $(9,8 \%)$ e ter "Boas expectativas" (9,8\%) com relação ao futuro profissional (esta última categoria encontrada principalmente entre estudantes dos cursos de Odontologia e Medicina, pertencentes aos grupos de maior renda familiar), estão outros estudantes que demonstram maior preocupação com seu futuro.

Bem acho que vou ser mais um desempregado, no entanto pretendo fazer uma pós-graduação para minimizar esse quadro. (Estudante de Fisioterapia - $7^{\underline{0}}$ período)

Nessa área do Serviço Social tenho medo de não encontrar mercado... (Estudante de Serviço Social - $2^{\underline{o}}$ período)

É ser uma profissional qualificada e estar pronta a competição deste árduo mercado de trabalho (Estudante de Serviço Social $2^{\underline{0}}$ período)

Me sinto insegura, confusa e em desespero quanto a este assunto. (Estudante de Nutrição - $10^{\underline{0}}$ período)

As categorias: "Espera encontrar dificuldades" $(8,1 \%)$, "Sobreviver com a profissão" $(2,7 \%)$ e "Espera ter condições de trabalho de qualidade" $(2,0 \%)$ sintetizam os depoimentos que expressam preocupação com o mercado de trabalho. Expressões como "confia ganhar o necessário pra sobreviver", "espera não morrer de fome", "confia não ficar desempregado", bem como "ter um salário justo", "encontrar um trabalho sem explorações e discriminações", "possibilidade de uma boa prática profissional" e até "necessidade de incentivos governamentais", foram mencionadas por muitos desses estudantes, argumentando sobre a crise econômica e as deficiências no campo do exercício profissional da saúde pública especialmente.

Observou-se, assim, muita preocupação com relação à inserção no mercado de trabalho, visto pela maioria dos estudantes das classes menos abastadas, como competitivo, saturado e difícil. Isto leva alguns deles a considerarem como necessário os estudos de pós-graduação, não apenas para aprofundar conhecimentos (principal argumentação entre os estudantes das classes mais abastadas), mas na esperança de que isso seja um diferencial positivo no processo de inserção no mercado de trabalho.
Quanto ao "lugar e às condições de trabalho" (Tabela 5), o aspecto mais mencionado nas respostas foi "Boas condições físicas" (ambiente limpo, organizado, claro, confortável, com bons equipamentos $-47,5 \%$ ). Os argumentos evidenciam que são condições nem sempre presentes em muitas das instituições públicas de saúde. Outras respostas destacam não apenas o aspecto material, mas acrescentam a necessidade de boas relações humanas, especialmente fazendo referência ao bom entendimento entre os profissionais. Assim, a categoria "Boas condições físicas e humanas" (19,7\%), ocupa o segundo lugar e 3,3\% das respostas mostraram a preocupação em enfatizar apenas as "boas relações interpessoais no ambiente de trabalho", sintetizada na categoria "Boas condições humanas". Alguns dos depoimentos apontaram o desejo de trabalhar em instituições públicas para complementar a prática privada $(12,2 \%)$ e outros, especificamente, na prática privada $(10,7 \%)$. Outras respostas, por sua vez, destacam a expectativa de trabalhar num local com "Liberdade de atuação/autonomia" (3,3\%).

Tabela 5

Lugar e condições de trabalho

\begin{tabular}{lc}
\hline \multicolumn{1}{c}{ Categorias } & $\%$ \\
\hline Boas condições físicas & 47,5 \\
Boas condições fisicas e humanas & 19,7 \\
Instituição pública complementando prática privada & 12,2 \\
Clínica particular /consultório & 10,7 \\
Boas condições humanas & 3,3 \\
Local com liberdade de atuação / autonomia & 3,3 \\
Não importa o local, mas o trabalho & 1,1 \\
Não sabe / Não respondeu & 2,2 \\
\hline Total & 100 \\
\hline
\end{tabular}

Gostaria de poder trabalhar em um local que me desse todas as condições. Equipamentos modernos, material, condições de higiene e segurança, etc. (Estudante de Enfermagem - $7^{\underline{0}}$ período)

Um local que pudesse oferecer condições de trabalho, tanto no seu plano físico, como de relacionamento entre pessoal, etc. (Estudante de Farmácia - $7^{\underline{o}}$ período)

Um local limpo e luxuoso. Consultório particular, trabalhando por minha conta e não trabalhando na sexta à tarde nem na segunda de manhã. (Estudante de Odontologia - $2^{\underline{o}}$ período)

Limpo, claro e organizado. Em um hospital com autonomia para tomar decisões. (Estudante de Enfermagem - $7^{\underline{o}}$ período)

Fica claro (e seria até esperado) que a grande maioria aspira trabalhar em ótimas condições, destacando a prática autônoma e o espaço físico e humano de máximo conforto. Contudo, não deixa de ser paradoxal, quando se sabe que uma grande parcela desses estudantes vai ser absorvida pelo serviço público, que foge dessas expectativas idealizadas. São poucos ainda os que apontam a preocupação de que esse espaço garanta também um ótimo atendimento para os usuários dos serviços. 
No referente "à idéia que os estudantes têm sobre as pessoas que procurarão seus serviços" (Tabela 6), boa parte das respostas destaca que estas precisam de uma "ajuda específica" $(38,3 \%)$, ou seja, de acordo com as atividades características de cada curso. A "ajuda geral e ampla”, independente da especificidade do curso, foi citada por $18,8 \%$ dos estudantes. Porém, um quarto das respostas enfatizou que as pessoas estão à procura de um profissional habilitado e competente capaz de resolver seus problemas, com expressões tais como: "são pessoas que precisam de mim, dos meus serviços e eu irei ter que tratá-los bem e ajudá-los no que puder" (Estudante de Fisioterapia - $1^{\underline{0}}$ período) ou "acham-me capaz de resolver seus problemas" (Estudante de Odontologia - $2^{\underline{o}}$ período).

Tabela 6

Idéias das pessoas que procurarão seus serviços

\begin{tabular}{lc}
\hline \multicolumn{1}{c}{ Categorias } & $\%$ \\
\hline Que precisam de ajuda específica & 38,3 \\
Que procuram um profissional habilitado e competente & 25,9 \\
Que procuram ajuda geral & 18,8 \\
Pessoas as mais variadas & 8,0 \\
Pessoas preocupadas com a saúde & 4,0 \\
Pessoas necessitadas /carentes & 2,8 \\
Não sabe / Não respondeu & 2,2 \\
\hline Total & 100 \\
\hline
\end{tabular}

Alguns estudantes simplesmente mencionaram mais objetivamente um público alvo abrangente ("as mais variadas pessoas") e $4 \%$ das respostas destacaram que seriam pessoas preocupadas com a saúde e prevenção. A preocupação pelas pessoas carentes ou necessitadas, usuárias dos serviços públicos de saúde, foi expressa apenas em $2,8 \%$ das respostas.

Foi importante, ainda, questionar sobre como viam a futura "relação profissional-paciente/cliente" (Tabela 7), a partir da escolha justificada de uma das quatro formas típicas dessa relação (Rotter \& Hall, 1992, citado por RodríguezMarín, 1995), brevemente descritas no próprio questionário. Além de ser um dado a considerar, o fato de que $20,3 \%$ dos estudantes não forneceram justificativa nenhuma, 42,2\% dos estudantes responderam como sendo do tipo mutualista, ou seja, baseada no diálogo, respeito e na troca de saberes:

Tabela 7

Relação profissional

\begin{tabular}{lc}
\hline \multicolumn{1}{c}{ Categorias } & $\%$ \\
\hline Mutualista & 42,2 \\
Mutualista contraditório & 23,5 \\
Clientelista & 11,6 \\
Paternalista & 2,4 \\
Não respondeu & 20,3 \\
\hline Total & 100 \\
\hline
\end{tabular}

A visão do profissional da saúde tem que ser dada por uma igualdade de atitudes perante o paciente. Todos fornecem conhecimento de uma maneira particular e todos também preci- sam ser olhados como um todo e não especificamente a patologia ou segmento que está sendo acometido. (Estudante de Fisioterapia - $7^{\underline{0}}$ período)

Acredito que o papel do cliente (usuário) dos serviços tem a contribuir também no trabalho do profissional dando sugestões, avaliando e participando das ações complementadas. Ele não é um ser passivo, mas um sujeito. (Estudante de Serviço Social - $9^{\underline{0}}$ período)

O meu trabalho é fruto de uma relação bidirecional, na qual o espaço é utilizado por ambos de forma igual, havendo respeito pelas forças do outro. Um não leva o outro a lugar algum, caminhamos juntos. (Estudante de Psicologia - $10^{\circ}$ período)

Contudo, em alguns argumentos $(23,5 \%)$ identificados com a categoria mutualista contraditório, apesar dos estudantes terem marcado a opção mutualista, fica claro um discurso autoritário e uma relação verticalizada, baseada no conhecimento e no saber técnico do profissional:

O paciente contribui com todos os sintomas, devendo dizê-los sinceramente e sem omitir nenhum e o médico deve analisar todos minuciosamente para depois dizer o diagnóstico. (Estudante de Medicina - $1^{\underline{0}}$ período)

O profissional deve entrar em acordo com o paciente/cliente sobre o melhor a se fazer, mas não é um simples informante, ele deve utilizar da sua autoridade como profissional (Estudante de Odontologia - $2^{\underline{o}}$ período)

Eu entro com a técnica, com o conhecimento. O paciente entra com sua força de vontade para superar a limitação. Eu mostro como. (Estudante de Fisioterapia - $3^{0}$ período)

A relação clientelista foi citada por $11,6 \%$ dos participantes e a justificativa mais premente para esse tipo de relação é que o cliente tem a liberdade de escolher ou não o tratamento proposto pelo profissional. Este é visto como aquele que disponibilizará os serviços procurados pelo cliente, embora alguns dos depoimentos destacassem também a relação hierárquica definida pela posse do conhecimento por parte do profissional. Observou-se que foi uma resposta mais comum entre estudantes dos cursos de Nutrição, Serviço Social e Odontologia:

O paciente é um cliente! Vai diz o que há, o profissional diagnostica e apresenta a solução. Agora cabe ao paciente aceitar ou não, podendo buscar outra opinião, assim como buscamos o melhor preço. Parece grosseiro, não deve ser ao pé da letra, saúde é diferente de produtos, mas de forma prática é mais ou menos por aí. (Estudante de Nutrição - $3^{\mathfrak{o}}$ período)

Há uma relação assimétrica. Embora o profissional se proponha a uma igualdade sua ação normalmente terá uma extensão maior que a do usuário. (Estudante de Serviço. Social - $9^{\underline{0}}$ período)

O paciente pode saber alguma coisa, mas o profissional é quem vai dizer-lhe o que fazer. (Estudante de Odontologia $2^{\underline{0}}$ período) 
Apenas 2,4\% dos estudantes mencionaram a relação paternalista. Segundo esses estudantes, é necessária a diferenciação de saberes, pois possibilita que o profissional se responsabilize e tome a maioria das decisões em virtude de seu conhecimento teórico-técnico:

É bem mais provável que o profissional tenha muito mais conhecimento do assunto que o paciente. Por isso ele deve ser o "dono da situação”. Isso (essa hierarquia) é necessária para haver ordem... (Estudante de Medicina - 4º período)

O profissional detém a informação que o paciente necessita. É necessário que haja essa desigualdade para existir respeito à autoridade do profissional... (Estudante de Medicina - $4^{\underline{0}}$ período)

O profissional deve realizar o seu tratamento do jeito que ele acha que está certo, afinal ele se especializou nisso, já o paciente deve apenas aceitar o que o profissional diz e realiza, pois ele não tem a formação que o profissional tem, apesar de às vezes o profissional poder estar errado. (Estudante de Odonto$\operatorname{logia}-2^{\underline{o}}$ período)

Embora seja difícil através da estratégia de questionário, ter uma idéia mais aprofundada das razões para uma ou outra escolha, é possível perceber a clara opção pela relação mutualista que define mudanças positivas na forma de considerar essa relação profissional-paciente/cliente. No caso específico de alguns depoimentos, ficou clara a preocupação por uma comunicação horizontal, pela qualidade do atendimento e a satisfação do usuário desse serviço. Contudo, em outros depoimentos foi priorizada com exclusividade a carga de capital intelectual como definidora de uma relação hierárquica e verticalizada. É um aspecto que pode ser confirmado pela forma dos mesmos estudantes se posicionarem em algumas das respostas dos outros itens, deixando de lado, como destaca Campos (1997), essa preocupação mais humanista do exercício profissional na área da saúde.

\section{Considerações finais}

As idéias e concepções hegemônicas relacionadas com a temática entre os estudantes dos diferentes cursos mostram um processo de formação no qual está ausente a concepção abrangente de saúde como eixo integrador comum no processo de treinamento na área. De fato, observa-se que a prevalência do modelo biomédico, hegemônico ainda no contexto social local, condiciona o universo simbólico dos participantes da pesquisa. Tal influência faz-se sentir, especialmente, entre estudantes da área biomédica, quando destacam a importância da formação teórica, das técnicas curativas em detrimento das preventivas e da ênfase ao aspecto biológico que subestima os aspectos psicológicos e sociais. Contudo, entre os estudantes das áreas não-biológicas, percebe-se também a visão fragmentada e restrita de saúde.

Constata-se que as relações sociais e as experiências significativas influenciaram substancialmente na escolha do curso. Outro dos argumentos que prevalece em quase todos os depoimentos é o intuito de ajudar as pessoas através das funções próprias de cada curso. Porém, percebe-se um marcado viés assistencialista permeando o sentido de tal ajuda. A análise do que os estudantes consideram como principais objetivos da profissão revelou ainda que cada curso tem uma visão parcializada do ser humano em virtude de suas práticas específicas. A preocupação por uma visão mais abrangente (uma perspectiva biopsicossocial) foi pouco mencionada, o que explica a dificuldade do trabalho em equipe e de um enfoque multidisciplinar em função da complexidade do ser humano.

Quanto aos aspectos mencionados como indispensáveis à formação profissional, destaca-se a necessidade de um sólido conhecimento teórico associado à prática, aliado a atributos de personalidade tais como esforço, empenho, decisão, iniciativa. Aspectos éticos e traços humanistas de personalidade (responsabilidade, sensibilidade, honestidade, humanidade) são também mencionados, até mesmo em maior proporção. Fica claro em muitos depoimentos que um dos principais objetivos é garantir o sucesso profissional, o qual é ratificado quando falam das expectativas profissionais que giram em torno de serem reconhecidos profissionalmente, tanto em status, quanto economicamente.

Observou-se, ainda, muita preocupação com relação à inserção no mercado de trabalho, visto pela maioria dos estudantes, especialmente da área não-biomédica e das classes menos abastadas, como competitivo, saturado e difícil. Isto leva alguns deles a considerarem como necessário os estudos de pós-graduação, não apenas para aprofundar conhecimentos (principal argumentação entre os estudantes das classes mais abastadas), mas na esperança de que isso seja um diferencial positivo no processo de inserção no mercado de trabalho.

Dentre as características de personalidade mais apontadas estão aquelas que denotam uma maior necessidade de ser ativo e empreendedor, em virtude de um mercado profissional que exige hoje um profissional competitivo, qualificado e até "agressivo" para vencer as limitações e adversidades do contexto social. Com relação ao lugar do trabalho, destaca-se que a grande maioria aspira trabalhar em ótimas condições, destacando a prática autônoma e o espaço físico e humano de máximo conforto. São poucos os que apontam a preocupação de que esse espaço garanta também um bom atendimento para os usuários dos serviços.

Destaca-se, então, como necessário, um equilíbrio entre a capacitação científica e uma formação humanística que privilegie uma visão abrangente e multifacetada de saúde, bem como a sensibilidade no processo de lidar com a realidade psicossocial das pessoas que precisarão dos serviços profissionais. Percebeu-se que, embora uma alta porcentagem dos estudantes tenha considerado que a relação profissional-paciente deve ser de tipo mutualista, os depoimentos e justificativas dados por quase um terço deles apontam uma relação assistencialista, vertical e hierarquizada, baseada nas relações de poder estabelecidas em função da posse de conhecimento.

Conclui-se entendendo o processo de formação profissional como um espaço de formação e desenvolvimento de idéias, valores e concepções desenvolvidas em função de 
condicionantes não apenas acadêmicos, mas econômicos, políticos, sociais e culturais. Considera-se que concepções e práticas de saúde humanizadas e comprometidas socialmente são mais prováveis de surgirem em escolas humanizadas e preocupadas com as necessidades da população, que incentivem o desenvolvimento da sensibilidade por parte de seus estudantes para uma ação mais participativa dos pacientes/clientes. É necessário, portanto, não apenas uma reformulação estrutural, mas também conceitual e ideológica desse processo.

Estamos conscientes de que não existem comportamentos ou ações separadas dos processos de significação e do sentido que as pessoas, como agentes sociais, fazem de suas experiências e condições de vida, sendo este, geralmente um processo irreflexivo (Traverso, 2001). É, portanto, indispensável refletir junto com os agentes sociais implicados sobre o universo simbólico que perpassa esses comportamentos e a relevância de que eles mesmos "construam" criticamente suas próprias alternativas, residindo, principalmente nessa atividade, a importância de continuar este tipo de pesquisa.

\section{Agradecimentos}

A pesquisa aqui relatada fez parte do Projeto Integrado "Comportamento no Trabalho e Saúde: um estudo com profissionais de saúde em Natal", apoiado pelo CNPq (Processo 520180/99-2). O desenvolvimento contou com a colaboração de Khris Evelyn Teixeira de Lima (bolsista de iniciação científica CNPq-balcão até dez/2001), Joilza da Conceição Rodrigues Rufino (bolsista de iniciação científica UFRNPIBIC/CNPq até dez/2001) e as estudantes voluntárias: Emília de Rodat P. de Araújo, Dianne Patrícia B. A. de Sousa e Talita de Oliveira Costa.

\section{Referências}

Almeida, M., Feuerwerker, L., \& Llanos, M. (1999). A educação dos profissionais de saúde na América Latina. Teoría e prática de um movimento de mudança. São Paulo: Hucitec.

Boltanski, L. (1989). As classes sociais e o corpo. Rio de Janeiro: Graal.

Byrne, N., \& Rozental, M. (1994). Tendencias actuales en la educación médica y propuesta de orientação para la educación médica en América Latina. Educación Médica y Salud, 28(1), 53-93.

Campos, G. W. S. (1997). Considerações sobre a arte e a ciência da mudança: revolução das coisas e reforma das pessoas. O caso da saúde. In L. C. O. Cecilio (Org.), Inventando a mudança na saúde (pp. 29-87). São Paulo: Hucitec.

Canesqui, A. M. (1995). Ciências sociais, a saúde e a saúde coletiva. In A. M. Canesqui (Org.), Ciências sociais, a saúde e a saúde coletiva (pp. 19-35). São Paulo: Hucitec/Abrasco.

Canguilhem, G. (1990). O normal e o patológico ( $3^{\mathrm{a}}$ ed.). Rio de Janeiro: Forense Universitária.

Capra, F. (1982). O ponto de mutação. São Paulo: Cultrix.

Kisil, M., \& Chaves, M. (1994). Programa UNI. Uma nova iniciativa na educação dos profissionais da saúde. Battle Creek: Fundação W. K. Kellogg.

Melo Filho, J. (1988). Concepção psicossomática: visão atual. Rio de Janeiro: Tempo Brasileiro.

Minayo, M. C. S. (1998). O desafio do conhecimento. Pesquisa qualitativa em saúde. São Paulo: Hucitec/Abrasco.

Organização Pan-americana de Saúde (1994). Los cambios de la profesión médica y su influencia sobre la educación médica. Educación Médica y Salud, 28(1), 7-19.

Pierantoni, C. R., \& Machado, M. L. (1994). Profesiones de salud: Una formación cuestionada. Educación Médica y Salud, 28(1), 199-210.

Rodríguez-Marín, J. (1995). Psicologia Social de la Salud. Madri: Síntesis.

Rosen, G. (1994). Uma história da saúde pública (2 $2^{\underline{a}}$ ed.). São Paulo: Hucitec/ UNESP/ABRASCO

Silva Junior, A. G. (1998), Modelos tecnoassistenciais em saúde. O debate no campo da saúde coletiva. São Paulo: Hucitec.

Traverso-Yépez, M. (1999). Os discursos e a dimensão simbólica: uma forma de abordagem à psicologia social. Estudos de Psicologia, 4(1), 39-60.

Traverso-Yépez, M. (2001). A interface Psicologia Social e saúde: perspectivas e desafios. Psicologia em Estudo, 6(2), 49-56.

1 Convém lembrar que no momento da elaboração final deste trabalho foi aprovado na Comissão de Constituição, Justiça e Cidadania (CCJC) do Senado, o Projeto de Lei (PL 025/2002). Este define o "Ato Médico" como "todos os procedimentos diagnósticos ou terapêuticos que envolvam a prevenção e os cuidados da atenção de saúde primária, secundária e terciária", condicionando ainda que "as atividades de coordenação, direção, chefia, perícia, auditoria, supervisão, desde que vinculadas, de forma imediata e direta a procedimentos médicos e, ainda, às atividades de ensino de procedimentos médicos privativos, incluem-se entre os atos médicos e devem ser unicamente exercidas por médicos”. Observa-se que todo o projeto está atrelado a um conceito de saúde estritamente biológico, o que o torna abusivo em relação às competências das outras categorias profissionais.

Martha Traverso-Yépez, doutora em Psicologia Social pela Universidad Complutense de Madrid, Espanha, é professora no Departamento de Psicologia da Universidade Federal do Rio Grande do Norte. Endereço para correspondência: Departamento de Psicologia UFRN; Caixa Postal 1622; Natal, RN; CEP 59078-970. Fone: (84) 215-3590. E-mail: traverso@ufrnet.br

Normanda Araújo de Morais era aluna do Curso de Psicologia da Universidade Federal do Rio Grande do Norte e bolsista de Iniciação Científica do CNPq quando da realização deste estudo. E-mail: normandaaraujo@bol.com.br 